\title{
The Curriculum Reforms of Introduction to Electronic Commerce Based on Flipped Classroom Concept
}

\author{
Xiaolan Feng \\ Xi 'an FanyiUniversity, Xi 'an Shaanxi,710105,China \\ 25345112@qq.com
}

\section{Keywords: Flipped Classroom; Course Reform; Electronic Commerce}

\begin{abstract}
There are some problems in teaching and learning Introduction to Electronic Commerce under the traditional teaching mode. With the continuous application of flipping the classroom ideas, it realizes students centered to improve the initiative and collaboration of learning, enlarging the depth and breadth of learning, which indicates the direction of the teaching reform of Introduction to Electronic Commerce. Besides, the paper proposes how to reform the teaching system of Introduction to Electronic Commerce, based on flipped classroom concept.
\end{abstract}

\section{Introduction}

With the continuous development of information technology, the teaching philosophy and teaching methods of the course are also closely followed by the times, such as tencent classroom, micro-class, flipped classroom, MOOC and so on. In recent years, the concept of flipped classroom has affected the global education community, whose educational theory and research have received much more attention from academics and teachers. The traditional teaching mode cannot meet the demands of modern talents.

Introduction to Electronic Commerce is a key course for students to truly understand e-commerce and interest in e-commerce. It is a basic framework and preliminary application for students to know e-commerce. However in learning, students learn much without deep understanding. Students tend to question the e-commerce itself. The students think that the major is flashy, which will affect the learning motivation and interest of the following specialized courses. Facing these challenges, the curriculum reform of modern information technology is imperative.

\section{The Current Situation of Introduction to Electronic Commerce Teaching}

Teaching is a combination of teachers' teaching and students' learning. But in teaching, we tend to focus only on teachers' teaching but ignore the core of learning, which exposes more defects in the current education environment.

Traditional Teaching Mode. At present, most private colleges adopt the traditional teaching mode. This kind of teaching mode is dominated by teachers and students are passive recipients of knowledge. There is a lack of close communication between students and teachers. Lectures, case studies, speeches and other teaching methods are often used in class. The focus of traditional teaching is "knowledge", and the goal of teaching is to "learn" knowledge and emphasize cognitive results.

Lack of Initiative in Learning. Under the traditional mode, students' learning initiative decreased significantly. The first thing is that what the teachers say and the students hear. The classroom was silent when the teacher asked the students to inquire. They only listened to teachers in class without consulting relevant information, auto-learning and thinking off class. Secondly, in the experiment class, the teacher should demonstrate the process to the students in addition to the principle of the experiment. Instead of evoking a solution to problems, students firstly ask teachers for help once they have problems. This kind of learning is always "learned," and students are not learning to solve problems.

Lack of Collaboration in Learning. At present, most of the students are studying on their own but lack of the team spirit. The main performance is when the teacher assigns some tasks to the 
team, the students tend to be solitary, and one student represents a team, for you don't see the results of other members in homework. In a group discussion, one of the group's students will often be seen talking, and the other people are listeners. These can be seen that the students themselves are seldom to communicate with each other in study, which can affect the students' thinking and judgment, and it is difficult to have new ideas in study. At the same time, the ability of students to communicate with others has not been well exercised and improved.

\section{Flipped Classroom Teaching Concept}

The popularization of the Internet and the application of computer technology in the field of education make the "flipped classroom" teaching model feasible and realistic.

Flipped Classroom Teaching. Flipped classroom refers to re-adjusting the time inside and outside the classroom, transferring the decision of learning from the teacher to the student. In "flipped classroom teaching mode", students finish their study Outside the classroom. The classroom becomes a place where teachers and students as well as students and students interact, including answering questions and using knowledge, so as to achieve better teaching results. The original idea for flipped classroom was from Jonathan Bergman and Aaron Sams at the American woodland park school. In 2007, they used recorded software to teach the courseware for teaching video, and posted it online for students who were unable to attend classes on time. With the pioneering teaching practice of the two teachers, this method has become a new teaching mode and gained more and more attention from teachers. Salman Khan is also a leader in flipped classroom teaching, and the khan academy he founded is known for flipped classroom teaching mode. The micro video program at khan academy is highly popular with students. Today, flipped classrooms have evolved into a new model of teaching that has spread across North America and across the world.

Features of Flipped Classroom. Why has flipped classroom been a big concern in recent years? This is because the "flipped classroom" in the traditional classroom has several distinct features:

(1) Play a technical advantage and make education with video.

(2) Break through the space and time limits of traditional classroom teaching.

(3) Optimize the teaching process according to the learning objectives.

(4) Accept learning and inquiry learning organic integration and complement each other.

(5) Give consideration to the cultivation of teaching and innovation ability.

As a kind of humanized classroom strategy, flipped classroom teaching mode provides personalized learning space and multiple learning approaches, realizing resource sharing and expanding teaching information. At the same time, cooperative communication and other activities stimulate students' learning motivation to a great extent, improve students' autonomous learning ability, and improve teachers' teaching skills. According to the results of foreign scholars, $50 \%$ of the students in the traditional classroom teaching failed in English and 44\% of the students failed in mathematics. After flipped classroom, the number of failed students dropped to 19 and 13 per cent respectively. Compared with the traditional classroom, the teaching effect has been greatly improved, so it has won the enthusiastic pursuit of many teachers abroad.

\section{Curriculum Reform under the Concept of Flipped Classroom}

Facing the current problems of "introduction to e-commerce", "Introduction to e-commerce" must be in the teaching mode, teaching content and teaching form to make changes, in order to improve the students' learning interest and initiative, a collaborative, train high quality applied creative talents. The continuous development and application of flipped classroom teaching concept provide direction for the reform of this course.

Transformation of Teacher Role. The teachers firstly should change their thinking mind based on flipped classroom concept. In traditional mode, the teacher is merely an "information" sender, and the students consolidate their review after class to master the knowledge and skills. But the student base is different; the degree that the student grasps also is different. Flipped classroom is a 
way in that students learn automatically. After class, students at their own pace to watch teaching courseware, and through the online way to communicate with peers and teachers, and then with questions in the discussion in the classroom, teachers guide the auxiliary role. Teachers are more of a problem solver in class than simple messaging. Teaching is more personalized.

Change the Teaching Process. Teaching should include the imparting of knowledge and internalization of knowledge. In traditional classroom, knowledge transmission takes place in the classroom, and the internalization of knowledge occurs outside the classroom. But in flipped classroom, real knowledge transfer and knowledge internalization are reversed, In this paper, students should use the online courseware to learn and receive knowledge before class. In class, teachers teach or carry out activities to help students master and use the new knowledge and skills learned before class, so that students can internalize their knowledge.

Reconstructing Teaching Contents and Teaching Methods. In the traditional teaching mode, most of the teaching is the textbook knowledge explanation, less auxiliary help and exploration. And based on the concept of flipped classroom, teaching content explanation, auxiliary help and exploration are average scores. In this way, the independence of students' thinking and the autonomy of learning are greatly improved. When designing the teaching content of a lesson, the teacher should first clarify the orientation of the class's teaching goal, which is to solve the problem. Second, design flipped classroom teaching, which is how to solve the problem. Under the flip class concept, first is to design basic knowledge into fine micro video class, let the student online learning before class, this not only saves the time of basic knowledge on class and help students to learn effectively, can solve the problem of learning differences. Secondly, through the pre-class online learning quiz to learn the degree of students' mastery, according to this design, targeted personalized help. In classroom can group discussion, students display, students mutual, questions and so on a variety of ways to solve the difficulty of the students' learning and improve the depth of the study, which stimulate students curiosity and exploring investigation, effectively promote the universality of learning. It is to cultivate the students' higher order thinking and not to be limited to low-order thinking.

Strengthening Teaching Interaction. The teaching interaction must be strengthened under the concept of flipped classroom. First of all, teachers can establish contact with students through advanced information technology such as QQ group and WeChat group. Meanwhile, they can understand the students' learning situation and solve the problems of learning in time. Secondly, when each task is carried out, teachers should learn to listen and analyze, and then communicate with students to form comments and summaries. This can effectively improve students' classroom participation and enhance their interest in learning.

Enhancing Process Evaluation. The traditional course evaluation is single, and the evaluation of students is the combination of the usual grades and final grades. Meanwhile, the final grades account for $70 \%$ of the total. In this way, the students' learning attention will be placed on the final exam results, and they are not concerned with their normal grades. This will affect the teachers' tasks in class and the effect of class. Based on the concept of flipped classroom, teachers must strengthen students' normal assessment. Based on the concept of flipped classroom, teachers must strengthen students' normal assessment, which is process evaluation. In the assessment, the pre-class test, class discussion, and the homework under the class are included in the normal performance. In group discussions, teachers should strictly rate the performance of each person. Encourage student demonstrations and students to innovate and incorporate them into their normal grades.

\section{Conclusion}

Introduction to Electronic Commerce is the first professional basic course for students majoring in e-commerce, which plays an important role in the cultivation of professional knowledge and professional interest. For present problems in teaching, the emergence of a new education concept in flipped classroom gives us a direction to solve problems. The teaching reform, based on the concept of flipped classroom, has achieved "students as the center", which has achieved the teaching of the students according to their aptitude, stimulated the students' interest in learning and 
improved the initiative and cooperation of learning, and realized my decision to be the master of my study. Improve the depth and breadth of learning. Definitely, there are some challenges to the implementation of the new education concept. For example, what if the students don't fit in with the video and quizzes before class? This will not be able to carry out activities in the classroom and directly affect the class. This requires that the teacher should not achieve a goal in the reform of the teaching, but should be the point to face, step by step, in accordance with the attempt -- summing up

-- the optimized steps to effectively carry out flipped classroom teaching.

\section{Acknowledgements}

Fund Project: "Web Programming Class Teaching Team" project built by Xi 'an Fanyi University teaching team (project No. : Z1312)

\section{References}

[1] Z.X. Song, Q.D. Yu: Journal of Distance Education,(2014)No1,p.96(In Chinese)

[2] J.Wang: Journal of Higher Education,(2016)No8,p.53(In Chinese)

[3] J.Wang, X.Xue,and C.L.Shi: E-Business Journal,(2017)No1,p.80(In Chinese) 